\title{
ANALISIS KELAYAKAN USAHATANI CABAI MERAH (Studi Kasus pada Kelompok Tani Mekar Subur Desa Maparah Kecamatan Panjalu Kabupaten Ciamis)
}

\author{
FEASIBILITY ANALYSIS OF RED CHILI FARMING \\ (Case Study Of Mekar Subur Farmers Group in Maparah Village, Panjalu Sub-District, \\ Ciamis Regency)
}

\author{
IIS RATNAWATI ${ }^{1 *}$, TRISNA INSAN NOOR ${ }^{2}$, DANI LUKMAN HAKIM ${ }^{1}$ \\ ${ }^{1}$ Fakultas Pertanian, Universitas Galuh \\ ${ }^{2}$ Fakultas Pertanian, Universitas Padjajaran \\ *E-mail : iisratnawati98@gmail.com
}

\begin{abstract}
ABSTRAK
Tujuan dari penelitian ini adalah untuk mengetahui : (1) Besarnya biaya, penerimaan dan pendapatan pada usahatani cabai merah per hektar per satu kali musim tanam di Desa Maparah Kecamatan Panjalu Kabupaten Ciamis, (2) Kelayakan usahatani cabai merah per satu kali musim tanam di Desa Maparah Kecamatan Panjalu Kabupaten Ciamis. Jenis penelitian yang digunakan dalam penelitian ini adalah studi kasus. Teknik penarikan sampel dalam penelitian ini dilakukan secara sensus, terhadap 12 orang petani. Hasil penelitian menunjukkan bahwa: (1) Biaya pada usahatani cabai merah di Desa Maparah Kecamatan Panjalu Kabupaten Ciamis rata-rata Rp. 57.515.062,37 per hektar per satu kali musim tanam. Sedangkan penerimaannya adalah Rp. 161.010.453 per hektar per satu kali musim tanam. Pendapatan pada usahatani cabai merah di Desa Maparah Kecamatan Panjalu Kabupaten Ciamis ratarata Rp. 103.495.391 per hektar per satu kali musim tanam. (2) R/C pada usahatani cabai merah di Desa Maparah Kecamatan Panjalu Kabupaten Ciamis rata-rata 2,80, artinya setiap pengeluaran biaya Rp. 1,00 maka petani mendapat penerimaan Rp. 2,80 dan keuntungan Rp. 1,8 dan layak untuk diusahakan.
\end{abstract}

Kata Kunci : Analisis Kelayakan, Cabai Merah, Usahatani, Pendapatan.

\begin{abstract}
The aimed of the study are to know: 1) the amount of costs, revenues and income on red chili farming per one planting season in Maparah Village, Panjalu Sub-District, Ciamis Regency, 2) feasibility analysis of red chili farming every one planting season. The research method used in this study was a case study. The sampling technique in the study was consist of census 12 farmers. Research results showed that : 1) costs for red chili farming in Maparah Village, Panjalu Subdistrict, Ciamis District, was Rp. 57.515.062,37 per hectare per one planting season. While revenue is Rp. 161.010.453 per one hectare per one planting season. Income on red chili was Rp. 103.495 .391 per hectare per one planting season. (2) $R / C$ ratio on red chili farming was 2,80 it concluded that every expenditure of $R p$. 1.00 , the farmer receives $R p$. 2,80 as revenue and $R p$. 1,8 as income, this the red chili farming were profitable.
\end{abstract}

Keywords : Farming, Feasibility Analysis, Revenue, Red Chili.

\section{PENDAHULUAN}

Indonesia merupakan negara agraris yang sebagian besar penduduk bekerja sebagai petani. Sektor pertanian merupakan salah satu sektor yang memberikan kontribusi yang sangat besar dalam perekonomian nasional dalam penyerapan tenaga kerja. Tanaman cabai besar telah dibudidayakan oleh petani 
secara luas di tanah air khususnya di Pulau Jawa (Djohar, 2015).

Analisis kelayakan usahatani adalah upaya untuk mengetahui tingkat kelayakan suatu jenis usaha, dengan melihat beberapa parameter atau kriteria kelayakan tertentu. Dengan demikian suatu usaha dikatakan layak jika keuntungan yang diperoleh dapat menutup seluruh biaya yang dikeluarkan baik biaya yang langsung maupun yang tidak langsung. Secara finansial kelayakan usaha dapat dianalisis dengan menggunakan beberapa indikator pendekatan atau alat analisis yaitu dengan menggunakan titik peluang pokok (Break Event Point), Revenue Cost Ratio (R/C ratio), Benefit Cost Ratio (B/C ratio), Payback period, dll (Prajnanta, Final dalam Waldi, 2017).

Cabai merupakan tanaman yang berasal dari bagian tropis dan subtropis Benua Amerika khususnya Amerika Selatan. Tanaman Cabai termasuk famili Solanaceae, genus Capsicum. Capsicum annuum $L$ merupakan salah satu spesies dari 20-30 spesies dalam genus yang sama. Spesies ini paling banyak dibudidayakan dan penting secara ekonomi. Berdasarkan karakter buahnya spesies Capsicum annuum digolongkan dalam empat tipe yaitu cabai besar, cabai keriting, cabai rawit dan paprika (Syukur, 2013).
Umumnya petani yang menjalankan usahatani cabai merah ini jarang sekali memperhitungkan biaya-biaya yang dikeluarkan secara terperinci. Selain itu mereka juga jarang mencatat berapa penerimaan yang diperoleh, besarnya biaya dan penerimaan petani dari usahatani yang sebenarnya mereka terima sulit untuk diketahui bahkan belum pernah menghitung besarnya $\mathrm{R} / \mathrm{C}$ dari usahataninya sehingga mereka tidak mengetahui apakah layak atau tidaknya usahatani cabai merah tersebut.

Berdasarkan dengan uraian tersebut, maka penulis tertarik untuk melakukan penelitian mengenai “Analisis Kelayakan Usahatani Cabai Merah yang merupakan Studi Kasus pada Kelompok Tani Mekar Subur Desa Maparah Kecamatan Panjalu Kabupaten Ciamis."

\section{METODE PENELITIAN}

Penelitian ini dilaksanakan pada petani Cabai Merah di Kelompok Tani Mekar Subur yang berada di Desa Maparah Kecamatan Panjalu Kabupaten Ciamis. Pemilihan lokasi dilakukan secara sengaja (purposive) dengan pertimbangan bahwa Kelompok Tani Mekar Subur merupakan kelompok yang rutin dan konsisten bertanam cabai merah.

Metode penarikan sampel yang digunakan dalam penelitian ini adalah 
sensus. Sampel dalam penelitian ini adalah petani cabai merah yang tergabung dalam kelompok tani Mekar Subur.

Metode penelitian yang digunakan dalam penelitian ini adalah metode kualitatif dengan jenis penelitian studi kasus.

Data yang digunakan adalah data primer dan data sekunder. Data primer adalah data yang diperoleh secara langsung dari responden dengan menggunakan alat bantu kuesioner, sedangkan data sekunder adalah data yang diperoleh dari dinas instansi terkait dan studi pustaka yang berhubungan dengan penelitian ini.

Untuk mengetahui analisis kelayakan usahatani cabai merah, maka analisis data yang digunakan adalah:

1. Analisis Biaya

$\mathrm{TC}=\mathrm{FC}+\mathrm{VC}$

Keterangan:

$\mathrm{TC}=$ Total Cost (Biaya Total)

$\mathrm{FC}=$ Fixed Cost (Biaya Tetap)

$\mathrm{VC}=$ Variable Cost (Biaya Variabel)

2. Analisis Penerimaan

$$
\mathrm{TR}=\mathrm{Y} . \mathrm{Py}
$$

Keterangan:

$\mathrm{TR}=$ Total Revenue $($ Penerimaan Total $)$

$\mathrm{Y}=$ Produksi yang diperoleh

Py $=$ Harga satuan produk

3. Analisis Pendapatan

$$
\mathrm{Pd}=\mathrm{TR}-\mathrm{TC}
$$

Keterangan:

$\mathrm{Pd}=$ Pendapatan

$\mathrm{TR}=$ Total Revenue (Penerimaan Total)

$\mathrm{TC}=$ Total Cost $($ Biaya Total $)$

4. Analisis R/C Ratio

$$
\mathrm{R} / \mathrm{C}=\frac{\text { Penerimaan Total }}{\text { Biaya Total }}
$$

Keterangan:

Revenue $=$ Besarnya penerimaan yang diperoleh

Cost $=$ Besarnya biaya yang dikeluarkan

\section{HASIL DAN PEMBAHASAN}

\section{Umur Responden}

Umur merupakan salah satu faktor yang dapat mempengaruhi kemampuan seseorang dalam bekerja, dikarenakan umur yang lebih muda cenderung lebih baik daripada yang sudah berusia tua karena kondisi fisik yang berbeda.

\section{Tabel 1. Kelompok Umur Responden Kelompok Tani Mekar Subur pada tahun 2018}

\begin{tabular}{llrr}
\hline No & $\begin{array}{c}\text { Kelompok } \\
\text { Umur } \\
\text { (Tahun) }\end{array}$ & $\begin{array}{r}\text { Jumlah } \\
\text { (orang) }\end{array}$ & $\begin{array}{c}\text { Persentase } \\
(\%)\end{array}$ \\
\hline 1. & $<27$ & 2 & 16,67 \\
2. & $28-50$ & 6 & 50 \\
3. & $51-79$ & 4 & 33,33 \\
& Jumlah & 12 & 100 \\
\hline
\end{tabular}

Tabel 1 menunjukkan bahwa umur responden kelompok tani Mekar Subur yang paling dominan pada umur $28-50$ 
tahun, hal ini menunjukkan petani cabai merah pada kelompok tani Mekar Subur berada pada usia produktif.

\section{Pengalaman Berusahatani}

Pengalaman berusahatani merupakan salah satu faktor penting dalam menentukan keberhasilan usahatani cabai merah, karena dengan pengalaman usahatani cabai yang dimiliki petani bisa mengatasi kesulitan-kesulitan maupun hambatan-hambatan yang mungkin terjadi saat usahatani berlangsung.

Tabel 2. Pengalaman dalam Berusahatani Cabai Merah pada Kelompok Tani Mekar Subur Desa Maparah Tahun 2018.

\begin{tabular}{ccrr}
\hline No & $\begin{array}{c}\text { Pengalaman } \\
\text { Usahatani } \\
\text { (Tahun) }\end{array}$ & $\begin{array}{c}\text { Jumlah } \\
\text { (orang) }\end{array}$ & $\begin{array}{c}\text { Persentase } \\
(\%)\end{array}$ \\
\hline 1. & $2-5$ & 3 & 25 \\
2. & $6-9$ & 9 & 75 \\
& Jumlah & 12 & 100 \\
\hline
\end{tabular}

Sumber : Kelompok Tani Mekar Subur Tahun 2019.

Berdasarkan tabel 2. menunjukkan bahwa pengalaman berusahatani responden yang tergabung di Kelompok Tani Mekar Subur beragam, tetapi pengalaman usahatani cabai sebagian besar $(75 \%)$ yang memiliki pengalaman $6-9$ tahun, hal ini menunjukkan anggota kelompok tani sudah paham bertanam cabai merah.

\section{Pendidikan Responden}

Tingkat pendidikan yang dicapai oleh responden adalah lulusan sekolah dasar sampai sekolah menengah atas. Keadaan tingkat pendidikan responden dapat dilihat pada tabel 3 .

Tabel 3. Tingkat Pendidikan dalam Berusahatani Cabai Merah pada Kelompok Tani Mekar Subur Desa Maparah Tahun 2018.

\begin{tabular}{|c|c|c|c|}
\hline No & $\begin{array}{c}\text { Tingkat } \\
\text { Pendidikan }\end{array}$ & $\begin{array}{l}\text { Jumlah } \\
\text { (Orang) }\end{array}$ & $\begin{array}{c}\text { Persentase } \\
(\%)\end{array}$ \\
\hline 1. & $\begin{array}{l}\text { Sekolah } \\
\text { Dasar }\end{array}$ & 8 & 66,67 \\
\hline & Sekolah & & \\
\hline 2. & $\begin{array}{l}\text { Menengah } \\
\text { Pertama } \\
\text { Sekolah }\end{array}$ & 1 & 8,33 \\
\hline \multirow[t]{2}{*}{3.} & $\begin{array}{l}\text { Menengah } \\
\text { Atas }\end{array}$ & 3 & 25 \\
\hline & Jumlah & 12 & 100 \\
\hline
\end{tabular}
pendidikan responden pada umumnya masih tergolong rendah, sebagian besar adalah tamatan sekolah dasar $(66,67 \%)$.

\section{Tanggungan Keluarga Responden}

Tanggungan keluarga responden petani cabai dapat dilihat pada tabel 12

Tabel 4. Keadaan Responden Berdasarkan Jumlah Tanggungan Keluarga

\begin{tabular}{cccc}
\hline No & $\begin{array}{c}\text { Tanggungan } \\
\text { Keluarga } \\
\text { (orang) }\end{array}$ & $\begin{array}{c}\text { Jumlah } \\
\text { (orang) }\end{array}$ & $\begin{array}{c}\text { Persentase } \\
(\boldsymbol{\%})\end{array}$ \\
\hline 1. & $<3$ & 4 & 33,33 \\
2. & $3-5$ & 8 & 66,67 \\
& Jumlah & 12 & 100 \\
\hline
\end{tabular}

Jumlah tanggungan keluarga menjadi tanggung jawab petani terhadap kelangsungan hidupnya selain itu juga 
mempengaruhi pendapatan dan pengeluaran keluarga petani. Dengan jumlah tanggungan yang besar maka petani akan memiliki tenaga kerja dalam keluarga yang lebih besar pula.

\section{Luas Lahan Usahatani yang Digarap}

Berdasarkan hasil wawancara langsung di lapangan, responden yang tergabung di Kelompok Tani Mekar Subur mengelola lahan 2,87 hektar dengan ratarata mengelola lahan 0,23 hektar per orang.

Tabel 5. Luas Lahan Usahatani Cabai Merah pada Anggota Kelompok Tani Mekar Subur Tahun 2018.

\begin{tabular}{ccrr}
\hline No & $\begin{array}{c}\text { Luas Lahan } \\
\text { Usahatani } \\
\text { Cabai } \\
\text { (Hektar) }\end{array}$ & $\begin{array}{c}\text { Jumlah } \\
\text { (orang) }\end{array}$ & $\begin{array}{c}\text { Persentase } \\
(\%)\end{array}$ \\
\hline 1 & 0,14 & 7 & 58,34 \\
2 & 0,21 & 1 & 8,33 \\
3 & 0,28 & 1 & 8,33 \\
4 & 0,42 & 2 & 16,67 \\
5 & 0,56 & 1 & 8,33 \\
& Jumlah & 12 & 100 \\
\hline
\end{tabular}

Tabel 5. Menunjukkan bahwa pada umumnya responden mempunyai luas lahan usahatani cabai kurang dari 0,5 hektar, artinya responden bertanam cabai dengan lahan yang masih sempit. Hal ini sejalan dengan pendapat Suratiyah (2006) menyatakan bahwa kepemilikan lahan dibawah 0,5 hektar tergolong petani dengan kepemilikan lahan sempit.

\section{Analisis Usahatani Cabai}

\section{Analisis Biaya}

Di Kelompok Tani Mekar Subur Desa Maparah rata-rata proses produksi usahatani cabai merah per hektar per satu kali musim tanam dapat dilihat pada Tabel 6.

Tabel 6. Rata-rata Biaya Produksi pada Usahatani Cabai Merah per Hektar per Satu Kali Musim Tanam pada Kelompok Tani Mekar Subur Desa Maparah.

\begin{tabular}{llr}
\hline No. & \multicolumn{1}{c}{ Komponen Biaya } & Jumlah Biaya (Rupiah) \\
\hline 1. & Biaya Tetap & \\
a. Penyusutan Alat $\quad 1.575 .496,10$ \\
b. Pajak Bumi dan Bangunan & Rp. $57.491,29$ \\
c. Bunga Modal Biaya Tetap & Rp. $1.638 .515,9$ \\
Biaya Tetap Total & Rp. 3.271.503,34 \\
2. Biaya Variabel & \\
a. Sarana Produksi & \\
- Benih & Rp. $285.714,3$ \\
- Pupuk NPK & Rp. 1.465 .854 \\
- Pupuk Kandang & Rp. $4.529 .616,7$ \\
- Furadan & Rp. 189.547 \\
- Pupuk TSP & Rp. 284.321 \\
- Pestisida & Rp. 8.265.853,7 \\
- Kapur Dolomit & Rp. 740.418 \\
- Rapia & Rp. 167.247 \\
b. Tenaga Kerja & Rp. 29.332.752,6 \\
c. Bunga Modal Biaya Variabel & \\
Biaya Variabel Total & Rp. $8.926 .620,21$ \\
& Rp. 54.278.536,59 \\
& Rp. 57.515.062,37 \\
\hline
\end{tabular}


Biaya total yang dihitung dalam penelitian ini meliputi biaya tetap total ditambah dengan biaya variabel total. Hasil perhitungan menunjukkan bahwa rata-rata besarnya biaya total yang dikeluarkan petani cabai merah di Desa Maparah adalah Rp. 57.515.062,37 per hektar per satu kali musim tanam.

\section{Penerimaan Usahatani Cabai Merah}

Tabel 7. Rata-rata Produksi, Harga Jual dan Penerimaan pada Usahatani Cabai Merah per Hektar per Satu Kali Musim Tanam pada Kelompok Tani Mekar Subur di Desa Maparah Tahun 2019.

\begin{tabular}{lllr}
\hline No. & \multicolumn{1}{c}{ Uraian } & Satuan & \multicolumn{1}{c}{ Jumlah } \\
\hline 1. & Produksi & $\mathrm{Kg}$ & $7.822,83$ \\
2. & Harga Jual & $\mathrm{Rp} / \mathrm{Kg}$ & 20.250 \\
3. & Penerimaan & $\mathrm{Rp}$ & 161.010 .453 \\
\hline
\end{tabular}

Penerimaan diperoleh dari jumlah seluruh produksi cabai merah yang dihasilkan dikalikan dengan harga jual pada saat penelitian, rata-rata hasil penerimaan dari usahatani cabai merah untuk satu kali musim tanam sebesar Rp. 161.010.453.

\section{Pendapatan Usahatani Cabai Merah}

Tabel 8. Rata-rata Penerimaan, Biaya Produksi Total dan Pendapatan pada Usahatani Cabai per Hektar per Satu Kali Musim Tanam pada Kelompok Tani Mekar Subur di Desa Maparah Tahun 2019.

\begin{tabular}{ccr}
\hline No. & Uraian & Jumlah $($ Rp) \\
\hline 1. & Penerimaan & 161.010 .453 \\
2. & Total Biaya & $57.515 .062,37$ \\
3. & Pendapatan & 103.495 .391 \\
\hline
\end{tabular}

Pendapatan merupakan selisih antara penerimaan dengan biaya total yang dikeluarkan. Hasil perhitungan menunjukkan besarnya pendapatan sebesar Rp. 103.495.391

\section{Analisis R/C}

Dengan menganalisis kelayakan usahatani dapat diketahui apakah usahatani tersebut layak atau tidak. Kelayakan usahatani cabai merah dapat dihitung menggunakan $\mathrm{R} / \mathrm{C}$. R/C diketahui dengan cara pembagian antara penerimaan dengan biaya total. Berdasarkan hasil penelitian maka R/C yaitu 2,80 artinya setiap pengeluaran biaya Rp. 1,00 maka petani cabai merah akan mendapat penerimaan Rp. 2,80 sehingga petani cabai merah memperoleh keuntungan Rp. 1,8. Nilai R/C yang semakin besar akan memberikan keuntungan yang semakin besar juga kepada petani dalam melaksanakan usahataninya.

\section{KESIMPULAN DAN SARAN}

\section{Kesimpulan}

Biaya pada usahatani cabai merah di Desa Maparah Kecamatan Panjalu Kabupaten Ciamis rata-rata Rp. 57.515.062,37 per hektar per satu kali musim tanam. Sedangkan penerimaannya adalah Rp. 161.010.453 per hektar per satu kali musim tanam. Pendapatan pada 
usahatani cabara merah di Desa Maparah Kecamatan Panjalu Kabupaten Ciamis rata-rata Rp. 103.495.391 per hektar per satu kali musim tanam.

R/C pada usahatani cabai merah di Desa Maparah Kecamatan Panjalu Kabupaten Ciamis rata-rata 2,80, artinya setiap pengeluaran biaya Rp. 1,00 maka petani mendapat penerimaan Rp. 2,80 dan keuntungan Rp. 1,8 dan layak untuk diusahakan.

\section{Saran}

Berdasarkan kesimpulan, maka disarankan agar kegiatan usahatani cabai merah di Kelompok Tani Mekar Subur Desa Maparah Kecamatan Panjalu Kabupaten Ciamis dipertahankan atau diteruskan, karena usaha yang dilaksanakan dapat memberikan keuntungan.

Bagi petani cabai merah diharapkan agar memperhatikan kalender penanaman agar keuntungan yang diperoleh dapat lebih maksimal namun tetap memperhitungkan hari-hari besar nasional maupun keagamaan.

\section{DAFTAR PUSTAKA}

Balai Penyuluhan Pertanian Kecamatan Panjalu. 2019. Laporan Tahunan 2018. Panjalu. BPP.

Damanik, Agri Mandasari. 2013. Analisis Perbandingan Kelayakan Usahatani Cabai Merah (Capsiccum Annum
L.) Dengan Cabai Rawit (Capsiccum Frutescens L.) (Studi Kasus : Desa Hinalang, Kecamatan Purba, Kabupaten Simalungun). Journal Social Economic Of Agriculture And Agribusiness Volume 4 No. 9 September 2015.

Djohar. 2015. Analisis Usahatani Cabai Merah Besar (Capsicum annuum L.). E-Jurnal Universitas Bojonegoro.

Furqonisa, Rahmah Yaumul. 2018. Analisis Produksi dan Kelayakan Usahatani Cabai Merah (Capsicum Annuum L.) di Desa Tanjung Ibus, Kecamatan Secanggang, Kabupaten Langkat). Journal Social Economic Of Agriculture And Agribusiness Volume 9 No. 11 November 2018.

Jumingan. 2011. Studi Kelayakan Bisnis Teori dan Pembuatan Proposal Kelayakan. Bumi Aksara : Jakarta.

Laurens, Reigana Gabriel. 2017. Analisis Kelayakan Finansial Usahatani Cabai Merah (Capsicum annum L.) di Desa Telaga Jernih, Kecamatan Secanggang, Kabupaten Langkat. Journal On Social Economic Of Agriculture And Agribusiness Volume 8 No 4 Oktober 2017.

Rasidin, dkk. 2018. Analisis Pendapatan Dan Efisiensi Pemasaran Cabai Merah (Capsicum Annuum L.) di Kecamatan Watangpulu Kabupaten Sidrap. Jurnal Pendidikan Teknologi Pertanian Volume 4 September Suplemen (2018) : S84S91.

Soekartawi. 2006. Analisa Usahatani. Raja Grafindo Persada. Jakarta. 2015. Ilmu Usahatani Edisi Revisi. Penebar Swadaya. Jakarta.

Syukur, M. 2013. Sukses Panen Cabai Tiap Hari. Penebar Swadaya. Jakarta. 2016. 8 Kiat Sukses Panen Cabai Sepanjang Musim. AgroMedia Pustaka. Jakarta. 
Wahyudi. 2011. 5 Jurus Sukses Bertanam Cabai. AgroMedia Pustaka. Jakarta.

Waldi. 2017. Analisis Kelayakan Usahatani Cabai Merah di Lahan Pasir Pantai Kecamatan Panjatan Kabupaten Kulon Progo. Jurnal Ilmiah Agritas Vol 1, No 1 (2017).
Wijoyo, P.M. 2015. Teknik Jitu Menanam Cabai di Musim Hujan. Bee Media Indonesia. Jakarta.

Winarno. F. G. 2017. Cabai : Potensi Pengembangan Agrobisnis dan Agroindustri. PT Gramedia Pustaka Umum. Jakarta. 